\title{
Enrichment of Resveratrol in Wine through a New Vinification Procedure
}

\author{
Raul Francisco Pastor ${ }^{1}$, Magdalena Raquel Gargantini ${ }^{2}$, Marcelo Murgo ${ }^{2}$, Sebastián Prieto $^{2}$, Humberto Manzano ${ }^{2}$, \\ Carla Aruani ${ }^{3}$, Claudia Inés Quini ${ }^{3}$, Maria-Isabel Covas ${ }^{4}$ and Roberto Héctor Iermoli ${ }^{1}$ \\ 1. Section Polyphenols, Wine and Health, Fourth Chair in Internal Medicine, Clinics Hospital, University of Buenos Aires, Buenos \\ Aires C1408FZB, Argentina \\ 2. Department Special Analytical Standards, National Wine Institute, Mendoza M5500AAR, Argentina \\ 3. Department Oenological and Sensory Studies, National Wine Institute, Mendoza M5500AAR, Argentina \\ 4. NUPROAS Handesbolag, Sicka Allè, Nacka 13165, Sweden
}

Received: July 17, 2015 / Accepted: July 30, 2015 / Published: July 30, 2015.

\begin{abstract}
Sulphur dioxide is used in the vinification process as an antimicrobial agent, but it is also considered as an important risk factor for liver diseases. Stilbenes have inhibitory effects on the growth of lactic acid bacteria strains isolated from wine. The authors investigated the viability of obtaining free- $\mathrm{SO}_{2}$ resveratrol-enriched red wines. Substitution of sulfite $(7 \mathrm{~g} / 100 \mathrm{~kg})$ for resveratrol $(150$ $\mathrm{mg} / \mathrm{L}$ and $300 \mathrm{mg} / \mathrm{L}$ ) in the vinification process did not change the basic physical and chemical properties of wine or its sensorial profile. To the best of the authors' knowledge this is the first time that this type of vinification procedure is reported.
\end{abstract}

Key words: Vinification, sulfur dioxide, resveratrol, wine, enrichment.

\section{Introduction}

Cabernet Sauvignon is one of the world's most widely recognized red wine grape varieties. It is grown in nearly every major wine producing country among a diverse spectrum of climates from Canada's Okanagan Valley to Lebanon's Beqaa Valley. Cultivation of the grape originally from France spread across Europe and to Australia and America where it can be found in places like California (Santa Cruz Mountains), Chile (Maipo Valley), and Argentina (Tunuyán). The classic profile of Cabernet Sauvignon tends to be full-bodied wines with high tannins and noticeable acidity that contributes to the wine's aging potential. In cooler climates, Cabernet Sauvignon has a propensity to produce wines with blackcurrant notes that can be accompanied by green bell pepper, mint, and cedar

Corresponding author: Raul Francisco Pastor, Ph.D., research fields: polyphenols, wine and health. E-mail: raulfranciscopastor@hotmail.com. ones all of which become more pronounced as the wine ages. In more moderate climates the blackcurrant notes are often seen with black cherry and black olives ones while in very hot climates the current flavors can veer towards the over-ripe and "jammy" side [1].

Traditional vinification is a common procedure which limits the contact with oxygen by the early addition of sulfur dioxide (sulfite, $\mathrm{SO}_{2}$ ) [2]. Nevertheless, whilst $\mathrm{SO}_{2}$ is commonly used as an antimicrobial agent and preservative in foods and wine, it has also been listed as an important risk factor for the initiation and progression of liver diseases due to oxidative damage [3]. Sulfite in wine and foods has been described as triggering asthma attacks [4]. The prevalence of sulfite sensitivity in the asthmatic population as a whole would be around $3.9 \%$, with steroid-dependent asthmatic patients being most at risk [5]. Due to this, different strategies and alternative methodologies are being carried out to reduce or to 
avoid the presence of sulfites in wines. Among them the use of natural fungicides (i.e. hexanal), dimethyl carbonate, lisozime, and modified atmosphere packaging, two controlled atmosphere, and both intermittent and continuous applications of $\mathrm{O}_{2}[2,6]$. Recently, interest has been focused on some natural components of wine, such as phenolic compounds, as an alternative to inhibit bacterial growth. Among wine phenolics, flavonols and stilbenes have shown the greatest inhibitory effects on the growth of lactic acid bacteria strains isolated from wine [7]. The authors hypothesized therefore that resveratrol could substitute sulfite as a preservative in wine. The introduction of stilbenes as a part of a whole vinification process has never been evaluated. This fact would also permit to increase the concentration of resveratrol, a polyphenol with bioactive properties $[8,9]$ in wines.

The aim of the pilot work was to investigate the viability of the substitution of sulfite by resveratrol in the vinification process and its effect on the basic chemical, physical, and sensorial indices of Cabernet Sauvignon red wines. The authors were also aimed to test the degree of enrichment of resveratrol in wines as a consequence of the procedure.

\section{Materials and Methods}

\subsection{Vinification Procedures}

The best Cabernet Sauvignon red grapes produced in vineyards of Tunuyán (Mendoza, Argentina) were picked, delivered to the pilot plant, and placed in a crusher-destemmer $(10 \mathrm{~L})$, with a temperature management system. At harvesting, grapes had a median sugar content of $26.2^{\circ} \mathrm{Brix}$; a titrable acidity of $4.61 \mathrm{~g}$ tartaric acid/L; and a $\mathrm{pH}$ of 3.86 .

The following different micro-vinification procedures were applied, using $100 \mathrm{~kg}$ of grapes for each trial:

Procedure 1. A traditional red vinification without resveratrol and with the addition of potassium metabisulfite $(7 \mathrm{~g} / 100 \mathrm{~kg})$, at commencement of the crusher destemmer process, decantation at $8-12{ }^{\circ} \mathrm{C}$ during 1.5 weeks, and fermentation performed at $17{ }^{\circ} \mathrm{C}-20{ }^{\circ} \mathrm{C}$ by $S$. cerevisiae, using ammonium phosphate $(15 \mathrm{~g} / 100 \mathrm{~kg})$ as a yeast nutrient.

Procedure 2. A red vinification with resveratrol at $150 \mathrm{mg} / \mathrm{L}$ and without potassium metabisulfite at commencement of the crusher-destemmer process, decantation at $8-12{ }^{\circ} \mathrm{C}$ during 1.5 weeks, and fermentation performed at $17^{\circ} \mathrm{C}-20^{\circ} \mathrm{C}$ by $S$. cerevisiae using ammonium phosphate $(15 \mathrm{~g} / 100 \mathrm{~kg})$ as a yeast nutrient.

Procedure 3. A red vinification with resveratrol at $300 \mathrm{mg} / \mathrm{L}$ and without potassium metabisulfite, at commencement of the crusher-destemmer process, decantation at $8-12{ }^{\circ} \mathrm{C}$ during 1.5 weeks and fermentation performed at $17^{\circ} \mathrm{C}-20^{\circ} \mathrm{C}$ by S. cerevisiae using ammonium phosphate $(15 \mathrm{~g} / 100 \mathrm{~kg})$ as a yeast nutrient.

Resveratrol was added as a $\beta$-cyclodextrin complex in microcapsules (Shanghai DND Pharm-Technology Co., Inc. Shanghai, China) for increasing its solubility and stability in wine.

\subsection{Fermentation}

The fermentation included, in the first $48 \mathrm{~h}$ after crushing, a maceration: the liquid phase was maintained in contact with the solid parts of grape (skin and seeds) at a constant temperature of $17^{\circ} \mathrm{C}$. After maceration, the entire bulk was pressed through a hydraulic press and the liquid phase was transferred in $25 \mathrm{hL}$ stainless steel tanks. The fermentation continued at a controlled temperature of $20{ }^{\circ} \mathrm{C}$ according to the sugar consumption. Subsequently, the liquid mass was subjected to an ageing in steel at a controlled temperature of $20^{\circ} \mathrm{C}$. Fermentation procedures lasted 13 days. The kinetic of fermentation was measured by hydrometry. After fermentation the wines were clarified with ovoalbumin, submitted to a first racking and after one week decantation, they were analyzed.

\subsection{Physical and Chemical Analyses}

The dry matter of the wines was determined by 
drying of $10 \mathrm{~mL}$ sample in a boron silicate glass over a water hot bath at $100{ }^{\circ} \mathrm{C}$. After evaporation, the sample was put in the oven until full drying. Alcoholic strength at $20{ }^{\circ} \mathrm{C}$ (expressed as \%vol), titrable acidity (expressed as $\mathrm{g}$ of tartaric acid/L), volatile acidity ( $\mathrm{g}$ acetic acid/L), sugar content $(\mathrm{g} / \mathrm{L})$, dry extract $(\mathrm{g} / \mathrm{L})$, and free and total sulphur dioxide $(\mathrm{mg} / \mathrm{L})$ were determined according to the regulations of the National Institute of Vinification, Argentina (http://www.inv.gov.ar/). The $\mathrm{pH}$ was also measured. Colour index was assessed by the relationship Intensity/Tone, were Intensity $=\mathrm{A} 420+\mathrm{A} 450$ and Tone $=\mathrm{A} 420 / \mathrm{A} 450$.

\subsection{Resveratrol Determination in Wines}

Trans-resveratrol was purchased from Sigma-Aldrich (Steinheim, Germany). Solvents used were of analytical grade, acetonitrile (JT Baker, Deventher, Nederlands), and formic acid (Sintorgan, Buenos Aires, Argentina). Standard solutions of trans-resveratrol in pure methanol (JT Baker, Deventher, Nederlands) were prepared. For resveratrol determination, wines were filtered through a membrane filter $(0.45 \mathrm{~lm})$ immediately after opening, and injected in the HPLC. Trans-resveratrol was determined by the HPLC method using an Agilent 1100 Series liquid chromatograph (USA) equipped with UV/DAD and fluorescence detectors. The analysis was performed on reversed phase Kromasil 100-5C 18 thermostatized $\left(35^{\circ} \mathrm{C}\right)$ column $(4.6 \mathrm{~mm}-250$ $\mathrm{mm}, 8 \mathrm{~mm}$ ) and formic acid/acetonitrile mobile phase. All injections were performed in triplicate.

\subsection{Sensory Analysis}

A descriptive method was used to define the sensory profile of the experimental bottled wines. A descriptive panel of 10 judges was employed. They have received some preliminary training sessions in order to develop a common vocabulary for the description of the sensory attributes of the Cabernet Sauvignon wine samples, and to familiarize themselves with scales and procedures.
Each attribute term was extensively described and explained to avoid any doubt about the relevant meaning. On the basis of the frequency of citation (> $60 \%) 27$ descriptors were selected to be inserted in the card: colour intensity, colour evolution, violet red, rust, dark red, bordeaux red, odour intensity, red fresh fruits, red mature fruits, marmalades, flower, aromatic herbs, spices, dry fruits, odor evolution, reduction, flavour, acidity, sweet tannins, drying tannins, concentration, finnish (persistency), bitter, fruitness, unctuosity, hot, and astringent (tactile in mouth). The wine samples were randomly evaluated by assigning a score between 0 (absence of the sensation) and 4 (extremely intense) in individual booths under incandescent white lighting. The analysis was performed by triplicate.

\subsection{Statistical Analyses}

The resulting scores between procedures were averaged and compared. In order to find significant differences among attributes between wines, ANOVA or Mann Whitney tests, according to the parametricity or not of the variables, were applied. The statistical data treatment was performed using the statistical package SPSS V12. Significance was applied at $P<$ 0.05 .

\section{Results and Discussion}

Results obtained in the analyses of the physical and chemical properties of Cabernet Sauvignon wines are reported in Table 1. No differences were observed among procedures. Fig. 1 shows the kinetics of fermentation in the different vinification procedures. No differences were obtained among them. Results of the sensory analyses showed that the majority of attributes examined were similar among $\mathrm{SO}_{2}$ and resveratrol wine making procedures (Fig. 2), although vinification with $300 \mathrm{mg} / \mathrm{L}$ of resveratrol provided the wine with the highest colour evolution, violet red, and colour intensity $(P<0.05$ versus Procedure 1$)$. The colour of red wines is one of the first features perceived by consumers that can greatly influence their 
Table 1 Quality parameters of Cabernet Sauvignon red wines obtained through four different wine-making procedures.

\begin{tabular}{llllllll}
\hline $\begin{array}{l}\text { Vinification } \\
\text { procedure }\end{array}$ & Alcohol $(\%)$ & Sugar $(\mathrm{g} / \mathrm{L})$ & $\mathrm{pH}$ & $\begin{array}{l}\text { Titrable acidity } \\
(\mathrm{g} \text { tartaric acid) }\end{array}$ & $\begin{array}{l}\text { Volatile acidity } \\
(\mathrm{g} \text { acetic } \mathrm{acid} / \mathrm{L})\end{array}$ & $\begin{array}{l}\text { Dry extract } \\
(\mathrm{g} / \mathrm{L})\end{array}$ & Colour index \\
1 & $15.5 \pm 0.15$ & $2.85 \pm 0.7$ & $3.9 \pm 0.09$ & $6.11 \pm 0.09$ & $0.18 \pm 0.01$ & $32.3 \pm 1.43$ & $1545 \pm 141$ \\
2 & $15.3 \pm 0.21$ & $2.93 \pm 0.99$ & $3.9 \pm 0.01$ & $5.64 \pm 0.03$ & $0.19 \pm 0.02$ & $32.8 \pm 1.73$ & $1798 \pm 97$ \\
3 & $15.6 \pm 0.14$ & $2.64 \pm 0.68$ & $3.7 \pm 0.02$ & $6.05 \pm 0.13$ & $0.18 \pm 0.01$ & $35.1 \pm 0.63$ & $1503 \pm 86$ \\
\hline
\end{tabular}

Procedures: 1, with potassium metabisulfite $(7 \mathrm{~g} / 100 \mathrm{~kg})$ and without resveratrol; 2, without potassium metabisulfite and with resveratrol (150 mg/L); 3, without potassium metabisulfite and with resveratrol (300 $\mathrm{mg} / \mathrm{L})$.

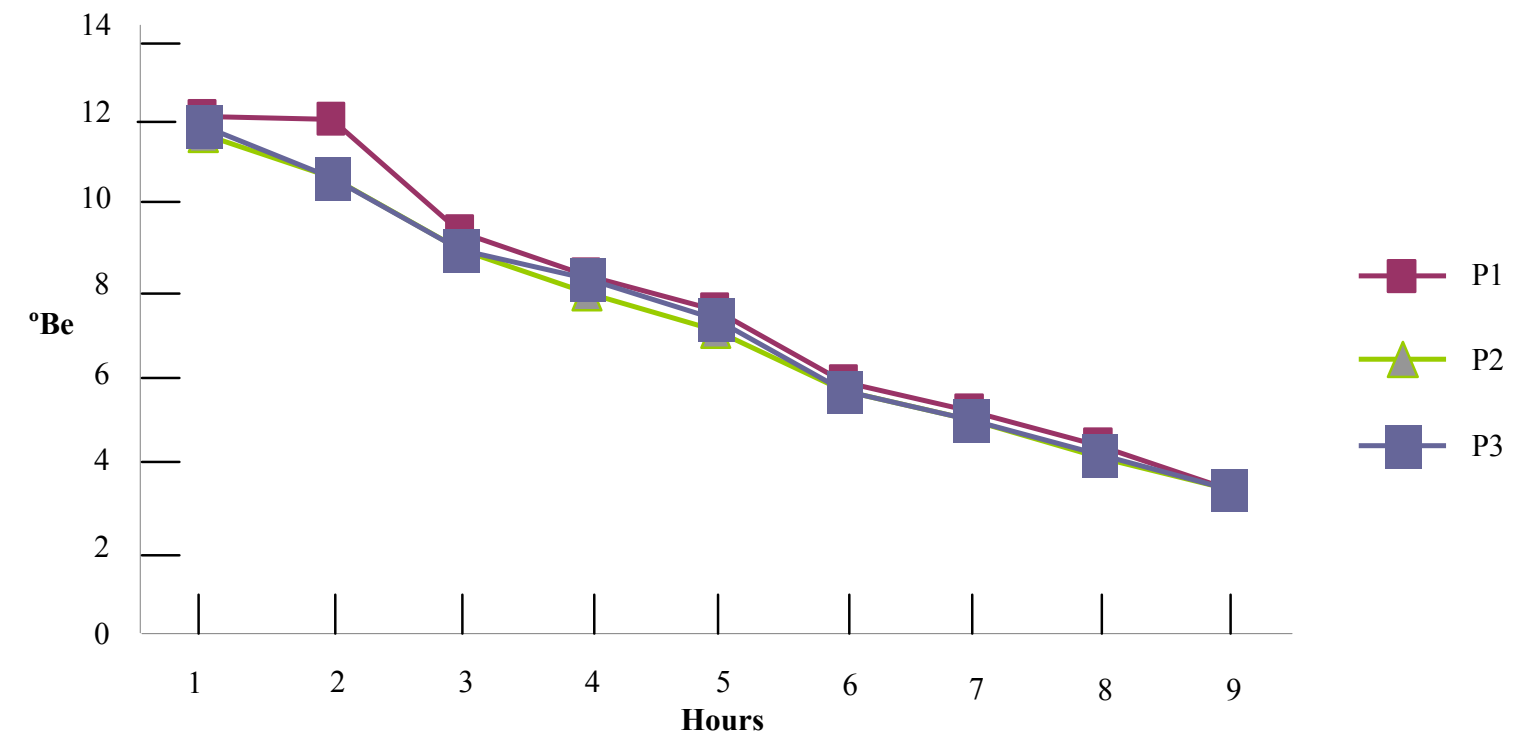

Fig. 1 Evolution of the fermentation process in the different vinification procedures. P1, vinification procedure without resveratrol and with addition of potassium metabisulfite $(7 \mathrm{~g} / 100 \mathrm{~kg}) ; \mathrm{P} 2$, vinification procedure with resveratrol at $150 \mathrm{mg} / \mathrm{L}$ and without potassium metabisulfite; $\mathrm{P3}$, vinification procedure with resveratrol at $300 \mathrm{mg} / \mathrm{L}$ and without potassium metabisulfite.

commercial acceptance. Wines are expected to be transparent and have intensive colour [10]. The mean final content of resveratrol in wine was: $2.42 \mathrm{mg} / \mathrm{L}$, $34.81 \mathrm{mg} / \mathrm{L}$, and $93.85 \mathrm{mg} / \mathrm{L}$ following procedures 1,2 , and 3 , respectively.

In the present work the authors describe a novel procedure in which resveratrol was used to replace potassium metabisulfite as an antimicrobial and preservative agent in the vinification procedure. From the results, a wine making procedure using resveratrol at $150 \mathrm{mg} / \mathrm{L}$ or at $300 \mathrm{mg} / \mathrm{L}$, and without sulfite, does not promote major changes in the basic physical, chemical, or sensorial properties of wine in comparison with the traditional vinification procedure using 7 $\mathrm{g} / 100 \mathrm{~kg}$ of potassium metabisulfite. Resveratrol, despite its antimicrobial and antifungic properties, at the above concentrations referred to did not change the fermentation kinetics. Due to this, the use of resveratrol alone is a promising tool for achieving a proper vinification without $\mathrm{SO}_{2}$.

Wine fermentation, clarification, cold stabilization, and filtration processes considerably affect resveratrol contents. However, the influence of microbiological processes is considered to be more important than that of physical and chemical ones [11]. The authors used the same yeast strain and no changes in the kinetics of the fermentation were observed among procedures. Other vinification steps, with exception of the substitution of sulfite by resveratrol, were also identical. Due to this we expected similar reductions in the resveratrol content between procedures. Percentages of recovery of resveratrol in wine in procedures 2 and 3 


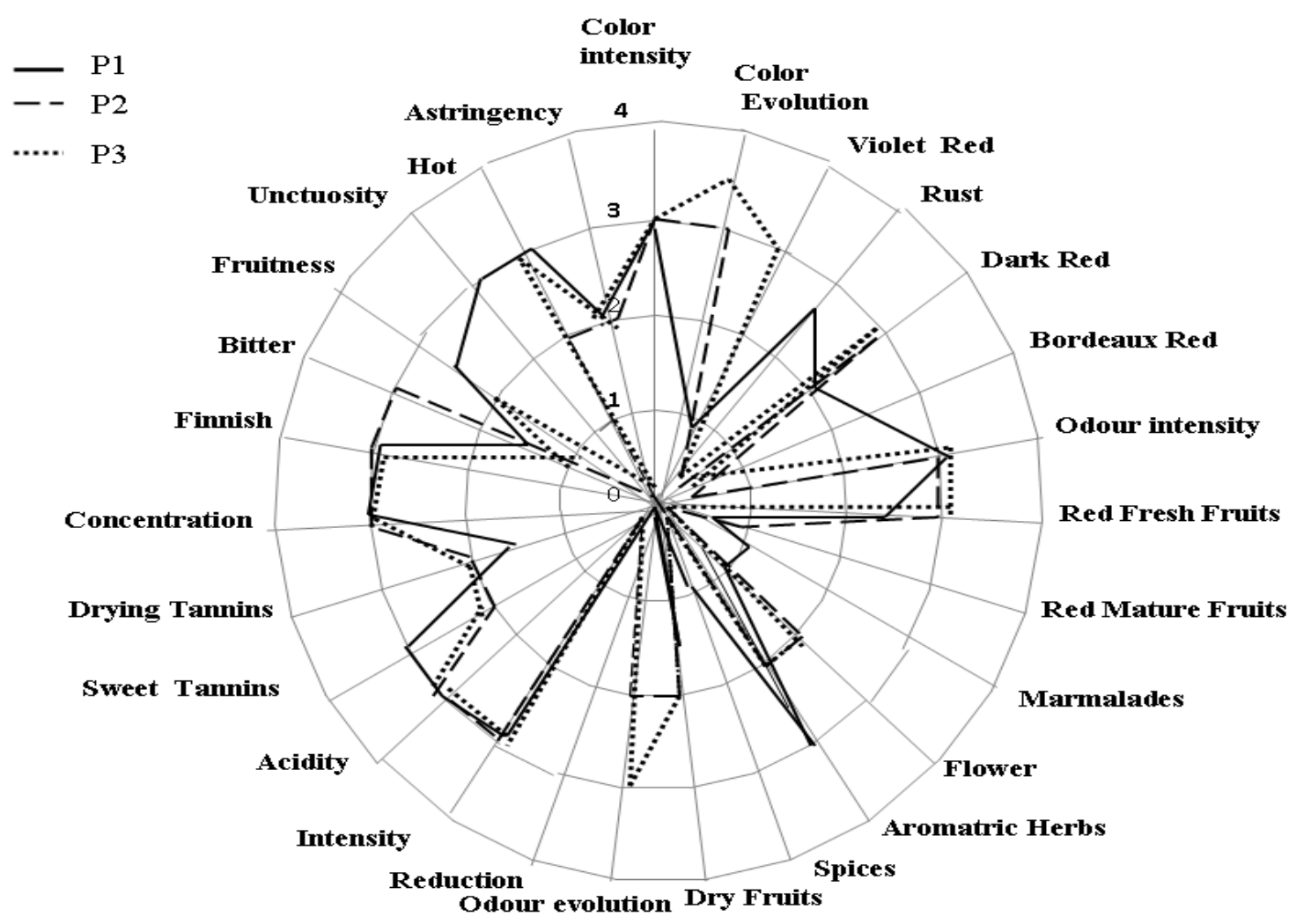

Fig. 2 Sensory profiles of wine with the different vinification procedures: P1, vinification procedure without resveratrol and with addition of potassium metabisulfite $(7 \mathrm{~g} / 100 \mathrm{~kg})$; $\mathrm{P2}$, vinification procedure with resveratrol at $150 \mathrm{mg} / \mathrm{L}$ and without potassium metabisulfite; $P 3$, vinification procedure with resveratrol at $300 \mathrm{mg} / \mathrm{L}$ and without potassium metabisulfite.

were around $25 \%-30 \%$ of the quantity of added resveratrol at the begining of the wine making procedures.

The added value of this new vinification procedure is that enriched-resveratrol wines were obtained. Alternative technologies have been looked at in an effort to increase the phenolic content (particularly resveratrol) in grapes postharvest. An increase up 2.5-fold in the resveratrol content has been reported after a $15 \mathrm{~h}$ anoxic treatment of the grapes, longer treatments leading to damaged grape [12]. With the authors' new vinification procedure we obtained wines with 14-fold and 39-fold resveratrol enrichments. Resveratrol, is a polyphenol that belongs to the stilbene family and occurs in relevant quantities in red wine [13]. Besides antimicrobial and antioxidant properties, resveratrol has been found to exert a wealth of pharmacological actions, such as anti-inflammatory, anticancer/proapoptotic, chemopreventive, antiangiogenic, and immunomodulatory $[8,9]$. Recently, but on the basis of a review concerning mainly studies in cell culture and animal models [14], a controversy has recently arisen concerning the potential benefits of resveratrol for human health [15]. As a consequence of the huge body of in vitro and in vivo findings a lot of effort has been engaged in the elucidation of the underlying mechanisms of resveratrol action. At present, however, all findings have not yet been translated into an approved clinical application. PubMed lists more than 40 clinical trials on resveratrol within the broad context of inflammation associated disorders, many of them dealing with diabetes, obesity, and coronary artery disease [9]. These studies often analyze inflammation-related parameters in the plasma (i.e., CRP, TNF $\alpha$, IL- $1 \beta$, and IL-6) and blood cells (i.e., activated kinases or 
transcription factors), or reported on functional parameters, such as the status of the endothelium [9, 16]. Nevertheless, whether these changes in secondary end points result in a clinically relevant improvement of disease severity or a reduced occurrence of disease-specific life-threatening events, have not been yet established. In a sub-sample $(n=1,000)$ of the PREDIMED (Prevención con Dieta Mediterránea) Study, high urinary levels of resveratrol metabolites were associated with a reduction in the prevalence of cardiovascular risk factors in high-risk patients [17]. Recently, in a cohort study $(\mathrm{n}=789)$ with older, Italian, community-dwelling adults, total urinary resveratrol metabolite concentration was not associated with cardiovascular disease, cancer, or all-cause mortality [18]. Further cohort studies with a large sample size or clinical intervention trials are required to establish the role of the concentration of resveratrol in biological fluids, or its effect on secondary end points, on primary end points for disease.

The length of time the grapes are left in the fermentation process determines the amount of the resveratrol wine contains. This is why red wine has a higher content than the white one. Depending on the geographical area, the type of vine, and the oenological methods adopted for production, red wine usually contains from $0.1-14.3 \mathrm{mg} / \mathrm{L}$ of resveratrol [19]. With the new vinification processes described in the work, besides avoiding the unhealthy properties linked to the addition of potassium metabisulfite, the quantity of wine resveratrol is increased. The American Heart Association recommends limiting alcohol consumption to one drink in women and two drinks in men preferably taken at meals [20]. With the authors' new processes of vinification one drink a day $(150 \mathrm{~mL})$ would provide around $5.25 \mathrm{mg}$ or $14.25 \mathrm{mg}$ of resveratrol. A concern has been raised among the safety of high resveratrol doses in humans. However, recent studies on the evaluation of the safety and potential mechanisms of activity following multiple dosing, have found resveratrol to be safe and reasonably well tolerate at doses of up to $5 \mathrm{~g} /$ day [21]. In human studies, a daily dose of $10 \mathrm{mg}$ of resveratrol has been shown to increase insulin sensitivity and reduce oxidative stress when administered during 4 weeks [22], and to improve endothelial function when administered during 3 months [23] to diabetic patients. Results of a recent meta-analysis indicate resveratrol as a promising tool in the management of type 2 diabetes patients [24]. Moreover, resveratrol is known to have a poor bioavailability when ingested from other sources but grape products [25]. Thus, increasing the content of resveratrol in wine can improve the effectiveness of the administered resveratrol dose.

\section{Conclusions}

Substitution of sulfite $(7 \mathrm{~g} / 100 \mathrm{~kg})$ by resveratrol at concentrations of $150 \mathrm{mg} / \mathrm{L}$ and $300 \mathrm{mg} / \mathrm{L}$ in the vinification process do not change the basic physical and chemical properties of wine, as well as its sensorial profile, but provides wine with a high intensity colour. As a consequence of the process an enrichment of resveratrol in wine occurs at quantities which have been proven to have benefits for health when moderate wine consumption. Further studies on the wine characteristics, other than the conventional ones, and of the health benefits of these wines are warranted. To the best of the authors' knowledge this is the first time that this type of wine making procedure has been reported.

\section{References}

[1] Robinson, J. 2012. "Wine \& Spirits Education Trust." In: Wine and Spirits: Understanding Wine Quality, Second Revised Edition, London.

[2] Pozo-Bayón, M. A., Monagas, M., Bartolomé, B., and Moreno-Arribas, M. V. 2012. "Wine Features Related to Safety and Consumer Health: An Integrated Perspective." Crit. Rev. Food Sci. Nutr. 52 (1): 31-54.

[3] Bai, J., Lei, P., Zhang, J., Zhao, C., and Liang, R. 2013. "Sulfite Exposure-Induced Hepatocyte Death Is not Associated with Alterations in p53 Protein Expression." Toxicology 312: 142-8.

[4] Field, P. I., McClean, M., Simmul, R., and Berend, N. 1994. "Comparison of Sulphur Dioxide and 
Metabisulphite Airway Reactivity in Subjects with Asthma." Thorax 49 (3): 250-6.

[5] Bush, R. K., Taylor, S., Holden, K., Nordlee, J. A., and Busse, W. W. 1986. "Prevalence of Sensitivity to Sulfiting Agents in Asthmatic Patients." Am. J. Med. 81 (5): 816-20.

[6] Baiano, A., Terracone, C., Longobardi, F., Ventrella, A., Agostiano, A., and Del Nobile, M. T. 2012. "Effects of Different Vinification Technologies on Physical and Chemical Characteristics of Sauvignon Blanc Wines." Food Chem. 135 (4): 2694-701.

[7] García-Ruiz, A., Moreno-Arribas, M. V., Martín-Álvarez, P. J., and Bartolomé, B. 2011. "Comparative Study of the Inhibitory Effects of Wine Polyphenols on the Growth of Enological Lactic Acid Bacteria." Int. J. Food Microbiol. 145 (2-3): 426-31.

[8] Pageni, R., Sahbi, J. K., Ali, J., Sharma, S., and Baboota, S. 2014. "Resveratrol: Review on Therapeutic Potential and Recent Advances in Drug Delivery." Expert Opin. Drug Deliv. 11 (8):1285-98.

[9] Fürst, R., and Zündorf, I. 2014. "Plant-Derived Anti-inflammatory Compounds: Hopes and Disappointments regarding the Translation of Preclinical Knowledge into Clinical Progress." Mediators of Inflammation (1): 146832

[10] Mazza, G. 1995. "Anthocyanins in Grapes and Grape Products." Crit. Rev. Food Sci. Nutr. 35 (4): 341-71.

[11] Roldán, A., Palacios, V., Caro, I., and Pérez, L. 2010. "Evolution of Resveratrol and Piceid Contents during the Industrial Winemaking Process of Sherry Wine." J. Agric. Food Chem. 58 (7): 4268-73.

[12] Jiménez, J. B., Orea, J. M., Urena, A. G., Escribano, P., De La Osa, P. L., and Guadarrama, A. 2007. "Short Anoxic Treatments to Enhance Trans-Resveratrol Content in Grapes and Wine." Eur. Food Res. Technol. 224: 373-8.

[13] Waterhouse, A. L. 2002. "Wine Phenolics." Ann. N. Y. Acad. Sci. 957: 21-36.

[14] Tang, P. C., Ng, Y. F., Ho, S., Gydad, M., and Chana, S. W. 2014. "Resveratrol and Cardiovascular Health. Promising Therapeutic or Hopeless Illusion?" Pharm. Res. 90: 88-115.

[15] Visioli, F. 2014. "The Resveratrol Fiasco.” Pharmacol Res. 90: 87.

[16] Tomé-Carneiro, J., Gonzálvez, M., Larrosa, M., Yáñez-Gascón, M. J., García-Almagro, F. J., Ruiz-Ros, J.
A. et al. 2012. "One-Year Consumption of a Grape Nutraceutical Containing Resveratrol Improves the Inflammatory and Fibrinolytic Status of Patients in Primary Prevention of Cardiovascular Disease." Am. J. Cardiol. 110 (3): 356-63.

[17] Zamora-Ros, R., Urpi-Sarda, M., Lamuela-Raventós, R. M., Martínez-González, M. A., Salas-Salvadó, J., Arós, F. et al. 2012. "High Urinary Levels of Resveratrol Metabolites Are Associated with a Reduction in the Prevalence of Cardiovascular Risk Factors in High-Risk Patients." Pharmacol Res. 65 (6): 615-20.

[18] Semba, R. D., Ferrucci, L., Bartali, B., Urpí-Sarda, M., Zamora-Ros, R., Sun, K. et al. 2014. "Resveratrol Levels and All-Cause Mortality in Older Community-Dwelling Adults." JAMA Intern. Med. 174 (7): 1077-84.

[19] Baur, J. A., and Sinclair, D. A. 2006. "Therapeutic Potential of Resveratrol: The in vivo Evidence." Nature Rev. Drug Discov. 5 (6): 493-506.

[20] Lichtenstein, A. H., Appel, L. J., Brands, M., Carnethon, M., Daniels, S., Franch, H. A. et al. 2006. "Summary of American Heart Association Diet and Lifestyle Recommendations Revision 2006." Arterioscler Thromb Vasc Biol. 26 (10): 2186-91.

[21] Patel, K. R., Scott, E., Brown, V. A., Gescher, A. J., Steward, W. P., and Brown, K. 2011. "Clinical Trials of Resveratrol." Ann. N. Y. Acad. Sci. 1215:161-9.

[22] Brasnyó, P., Molnár, G. A., Mohás, M., Laczy, B., Cseh, J., Mikolás, E. et al. 2011. "Resveratrol Improves Insulin Sensitivity, Reduces Oxidative Stress and Activates the Akt Pathway in Type 2 Diabetic Patients." Br. J. Nutr. 106 (3): 383-9.

[23] Magyar, K., Halmosi, R., Palfi, A., Feher, G., Czopf, L., Fulop, A. et al. 2012. "Cardioprotection by Resveratrol: A Human Clinical Trial in Patients with Stable Coronary Artery Disease." Clin. Hemorheol Microcirc. 50 (3): 179-87.

[24] Hausenblas, H. A., Schoulda, J. A., and Smoliga, J. M. 2014. "Resveratrol Treatment as an Adjunct to Pharmacological Management in Type 2 Diabetes Mellitus-Systematic Review and Meta-Analysis." Mol. Nutr. Food Res. 59 (1): 147-59.

[25] Ortuño, J., Covas, M. I., Farré, M., Pujadas, M., Fitó, M., Khymenets, O. et al. 2010. "Matrix Effects on the Bioavailability of Resveratrol in Humans." Food Chem. 120: 1123-30. 